\title{
MicroscopyPioneers \\ Pioneers in Optics: Daniel Barbaro
}

\section{Eric Clark}

From the website Molecular Expressions created by the late Michael Davidson and now maintained by Eric Clark, National Magnetic Field Laboratory, Florida State University, Tallahassee, FL 32306

eclark@magnet.fsu.edu

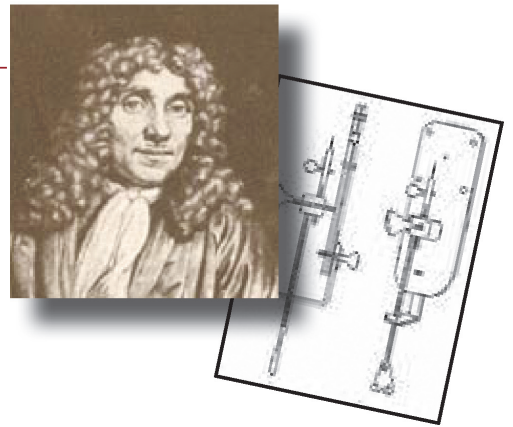

\section{Daniel Barbaro \\ (1514-1570)}

In the centuries preceding the invention of photography, oftentimes a device known as the camera obscura was used to help an artist produce a more realistic image of the subject. Latin for "dark chamber," the camera obscura in its earliest form consisted of a modest darkroom with a small hole (aperture) strategically placed in a wall or window shutter so that light could pass through it, producing an inverted image of the subject placed outside

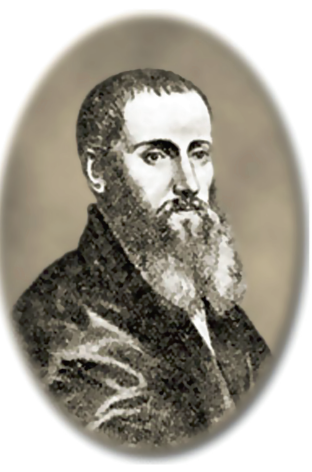
of the room on a whitened wall opposite the aperture. The principle upon which the camera obscura was based is believed to have been known by ancient philosophers but was not likely used as an aid for drawing until about five hundred years ago. One of the earliest descriptions of the camera obscura's use for such a purpose can be found in the notebooks of Leonardo da Vinci (1452-1519).

Similar to Leonardo, Daniel Barbaro was an Italian who encouraged the use of the camera obscura for artistic endeavors. By the time he adapted the technique, however, the chamber of the camera obscura was typically a simple box rather than an entire room. Little has been established with certainty about the personal life of Barbaro. He is known, however, to have been born around 1514 in Venice and to have died in 1570. Also, it may be assumed that the nobleman was well educated, since he is credited with translating ten books on architecture written by the celebrated Roman engineer Vitruvius and composed his own work La pratica della perspettiva (Practice of Perspective), which was published in 1568.

An extremely influential work during the sixteenth century, Daniel Barbaro's treatise on perspective includes the earliest known account of a lens being used with the camera obscura, bringing the device one step closer to the modern-day camera. The improvement in the image obtained with the device brought about by the inclusion of a lens, as well as by adjusting the distance upon which the image is to be projected, was described by Barbaro:

"Close all shutters and doors until no light enters the camera except through the lens, and opposite hold a piece of paper, which you move forward and backward until the scene appears in the sharpest detail. There on the paper you will see the whole view as it really is, with its distances, its colours and shadows and motion, the clouds, the water twinkling, the birds flying. By holding the paper steady you can trace the whole perspective with a pen, shade it and delicately colour it from nature."

Also according to Barbaro, "You should choose the glass which does the best, and you should cover it so much that you leave a little in the middle clear and open and you will see a still brighter affect." The glass that reportedly worked best for Barbaro was a bi-convex lens taken from a pair of ordinary spectacles, though he also experimented with concave lenses with little success. By the eighteenth century, other pioneers in optics had improved the camera obscura to an even greater extent by using multiple lenses and mirrors to create brighter, erect images.

MT

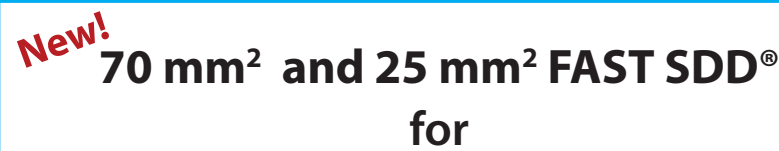

EDS (SEM) Applications

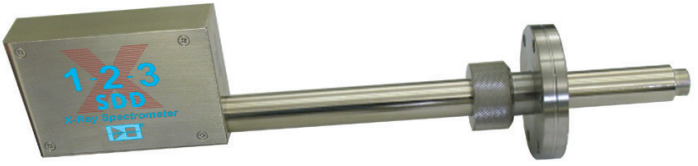

Amptek's new FAST SDD ${ }^{\circledR}$ detectors for EDS use with SEMs utilize "C2 Series" X-ray windows $\left(\mathrm{Si}_{3} \mathrm{~N}_{4}\right)$ and have excellent low energy response. Its high intrinsic efficiency makes it ideal for EDX, XEDS, EDXA and EDXMA.

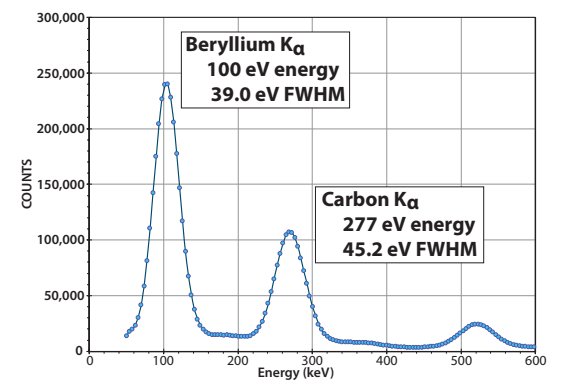

OEM's \# 1 Choice 


\section{SEM \& TEM Sample Preparation}

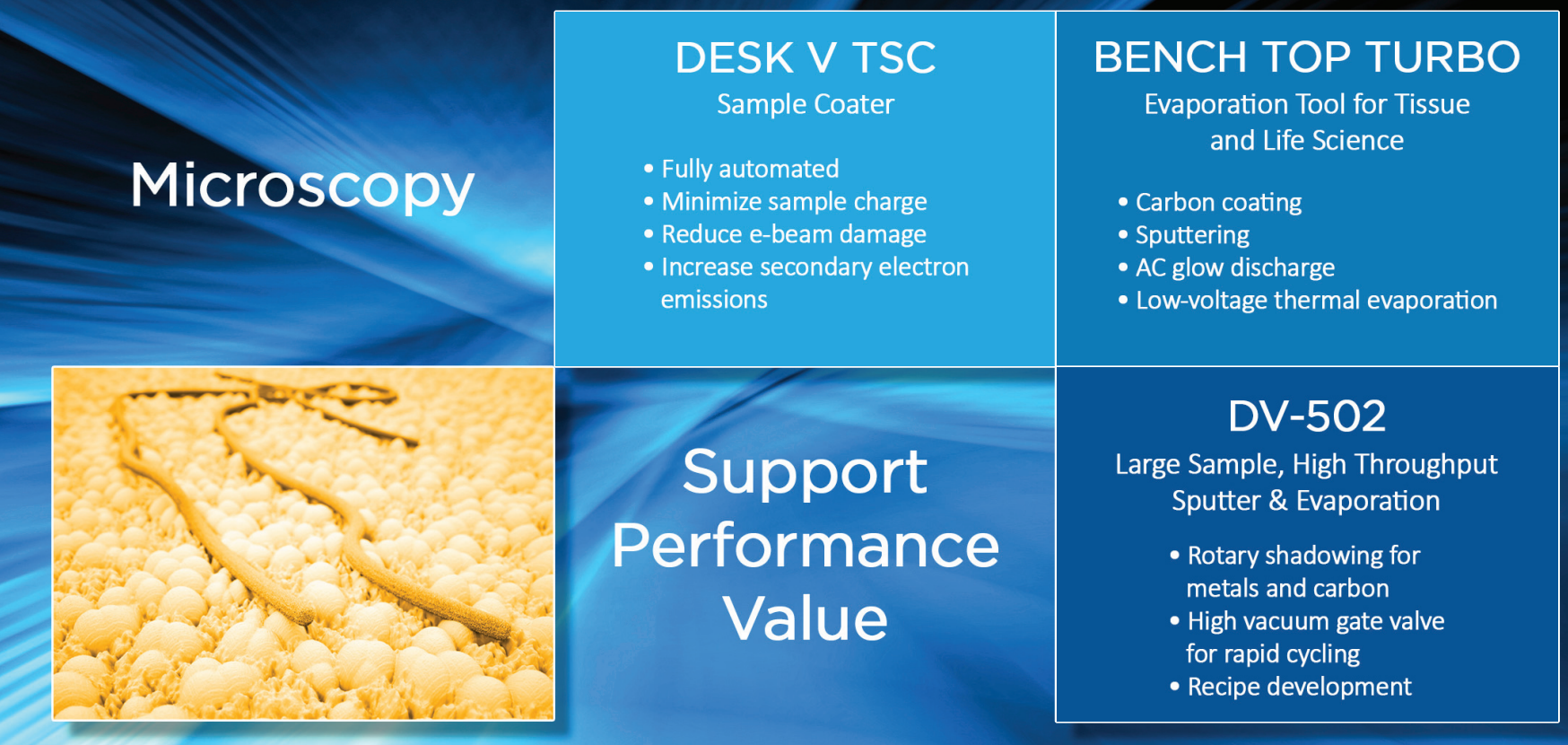

\section{Evactron plasma cleaning gives you the fastest carbon removal rate}

New Evactron ${ }^{\circledR}$ E50 Plasma Cleaner for your Vacuum System

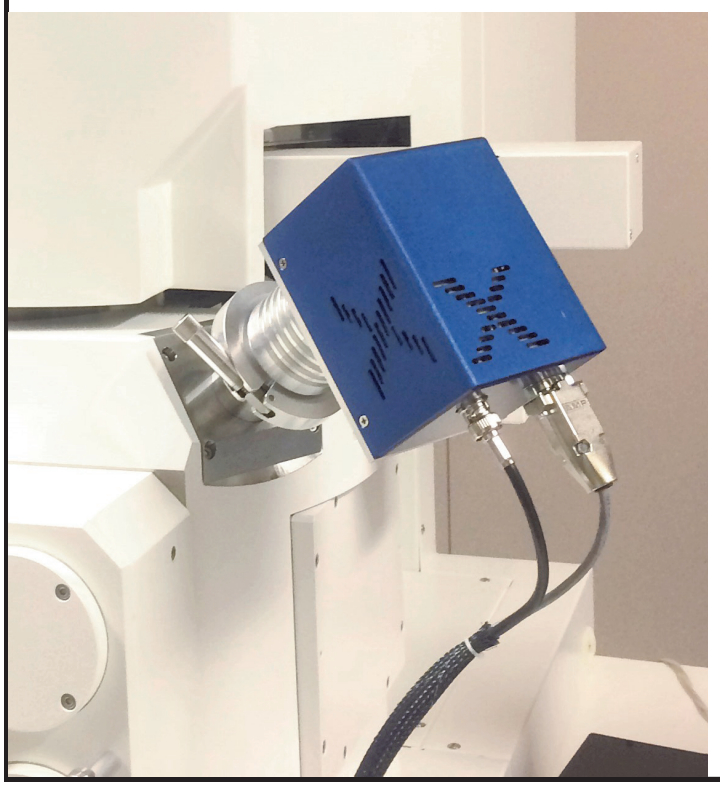

- New External Hollow Cathode Plasma Source

- 50 Watt max power for fast chemical etch

- No sputter etch damage or debris

- "POP'м" Ignition at high vacuum - no venting

- Push button or bluetooth GUI operation

- Less downtime for cleaning and pumpdown Lowest cost + best performance $=$ best value Have it all with the Evactron E50 De-Contaminator. The Fastest Way to Pristine ${ }^{\text {TM }}$

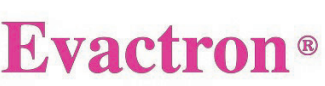

